\title{
International academic mobility across space and time: The case of Indian academics
}

\begin{abstract}
Internationalization has become a central feature of academic careers as academics are increasingly expected to be mobile. Yet we still know relatively little about the actual patterns and drivers of academic mobility across space and time. Using unique data from a recent survey of around 4,600 Indian academics across the globe, this article examines the dynamics of international academic mobility among one of the largest global academic diasporas. Overall, we find a strong 'pathdependency' of academic career and mobility trajectories, demonstrating the considerable importance of prior career steps in shaping future mobility choices. Working abroad as an academic, particularly in an Anglo-Saxon destination, becomes very unlikely without some early international study experience. However, contextual and individual-level factors may moderate this path-dependency. Younger generations of Indian researchers, men, high-performing students and those with (Indian) degrees that are more valued internationally, have higher chances of breaking the path. In addition, socioeconomic background seems to be an important driver for early career and mobility steps but becomes much less relevant for future academic employment.
\end{abstract}

Keywords: International academic mobility, path-dependency, India 


\section{Introduction}

Internationalisation has become a central feature of academic careers, either through long- or short-term physical mobility, or through international collaborations in research projects. According to Musselin, international mobility is a "kind of professional standard in some academic disciplines" (2004:73). At the same time, governments as well as higher education institutions and research centres are competing globally to attract the "best and the brightest" (Kapur and McHale 2005), thus encouraging and stimulating the international mobility of students and researchers.

Understanding the factors that drive this mobility is therefore of increasing concern, both to academics themselves and to policy makers. Prior studies have highlighted some of the drivers of international academic mobility, emphasising the crucial role of the quality and prestige of institutions in attracting students and researchers (King 2002; Ackers 2005). Material aspects (e.g. fees, scholarships, wages) were also found to be important in triggering mobility, as well as individuals' social background, gender and social capital (e.g. access to international personal and professional ties) (see for example Bauder 2015; King and RuizGelices 2003; Brooks and Waters 2010). For the most part, prior research on this issue has adopted a cross-sectional, variable-centred analysis and paid little attention to the temporal context of migration (see Sage et al. 2013; Carlson 2014; Kou and Bailey 2014; Faggian et al. 2006 for some notable exceptions). However, we expect the temporal (and geographical) sequence of moves among academics to be highly influential in their future mobility choices, perhaps more so than for any other type of migrants. In this paper, we thus replace the analysis of migration as a singular event within the life-course of individuals by an examination of their mobility trajectories over time. More specifically, we study the importance of prior migration stages in shaping academics' subsequent geographic mobility choices, as well as the factors that moderate the path-dependency of international academic careers.

The academic world is hierarchical, and research universities in highly developed, mostly Western, countries are at the core of the international knowledge system, while the academic profession in most developing countries is a profession on the periphery of the global scientific core (Shils 1972, Altbach 1998). This paper focuses on the case of India, whose higher education system is the third largest in the world (Altbach 2011). India has the largest worldwide diaspora of researchers, with 40 per cent of Indian-born researchers working overseas (Friedman 2006). Its internationally mobile students in many of the major (mostly Western) academic destinations form one of the largest groups (UNESCO/UIS 2015), and its outbound mobility rate is expected to outpace that of China by 2020 (British Council 2012).

Students and academics trained and employed in developing countries such as India often fall short of the academic standards and practices which prevail at the core of the global knowledge system. Thus, many young and bright students with good prospects for an academic career decide, some at an early stage of their career, to choose an international academic pathway that may open up greater academic opportunities and career prospects than would a higher education institution in their home country. Some of them remain in their 
country of destination to work as researchers, while others return to their origin countries, which generally values foreign academic training and international degrees (Altbach 2012, Sabharwal and Varma 2016). Still others move on to other foreign countries in order to further their studies or take up an academic or research job.

Previous research has studied the international mobility of students and that of academics separately, giving rise to two areas of literature that rarely communicate with each other. Yet evidence shows that a large share of academics working abroad have previously studied abroad, most often in the same country as that in which they are now working (Van de Sande et al. 2005; Hansen 2003). Thus, examining what drives the migration of academics should also imply an analysis of drivers of student mobility and the retention of students by the destination countries. Using new and unique data from an online survey of Indian researchers around the world which collects retrospective information on their academic and geographical trajectories, this paper contributes to the literature by bridging the two avenues of research and analysing, in a unitary framework, drivers of international migration for study and for academic work reasons.

The second contribution that this paper makes is to quantify the extent to which prior migration decisions influence subsequent mobility choices in academic careers. The importance of past migration experience for future moves has been acknowledged by existing studies, but few of these have gone beyond a descriptive assessment of the phenomenon. In this paper we investigate the extent to which individual academic careers are (geographically) path-dependent by assessing the importance of studying abroad for the likelihood of being employed abroad as a researcher. We further explore the factors which may moderate the observed path-dependency, or, in other words, those factors which may help students and researchers 'break the geographical path' of their academic careers. We explore the influence of both contextual factors - such as the discipline, location, or time period in which these careers started unfolding - and of individual factors, such as the scores researchers had obtained for their final high school exam, their gender or their social origin.

\section{Academic career trajectories and path-dependency a. Determinants of international academic mobility}

The international mobility of researchers and academics has so far received less academic attention than that of other high-skilled professionals such as physicians or IT workers. Academics, however, are increasingly expected to be mobile ${ }^{1}$ (Ackers 2001; 2005), perhaps to a larger degree than other professionals (Chompalov 2000; Franzoni et al. 2014). International experience has become necessary for career progression in many academic labour markets, though to a different degree across national contexts and disciplines (Ackers 2001). According to Chompalov (2000), natural scientists are more likely to emigrate than social scientists. On the one hand this may be due to the fact that their knowledge is "more readily convertible" (2000:17); on the other, it may reflect the higher importance of physical

\footnotetext{
${ }^{1}$ This "expectation of mobility" that increasingly characterizes academia may be seen as a sector-specific form of a "culture of migration" (Cohen 2004)
} 
access to high-quality infrastructures. However, it has been argued that social sciences and other disciplines outside the hard sciences experience a similar trend, though perhaps international experience is still less essential to their profile than it is to natural scientists (Ackers 2001: p. 71).

The importance of the expectation of mobility also varies by national context. Students and researchers from countries at the core of international knowledge systems, such as the US or UK, are less pressured to move abroad; for the others, including continental Europeans, a "foreign stint is seen as a feather in a postdoc's professional cap" (Balter 1999). For the latter, the pressure to move abroad comes both from reduced education and employment opportunities at home - a situation that academic migrants share with other categories of migrants - and from the premium attached to international exposure, which is more specific to the academic profession (Ackers 2001). Thus, geographical mobility is not so much a choice as a necessity to be embraced by those who want to progress in research and academic careers, blurring, to some extent, the boundary between "voluntary" and "forced" in the case of international academic mobility (King 2002).

Analyses of international academic mobility mostly examine the motivations triggering such moves, and, to a lesser extent, the enabling or constraining factors. Some recent studies contextualise academic mobility by situating it within the larger macro-economic context (Findlay 2011) or within the broader life-course of the individuals (Sage et al. 2013; Carlson 2014). Relatively more work has focused on the international migration of students - either for degree or for credit - than on academics in general. Since this paper views the two as intrinsically related, this section examines both areas of literature, which have thus far remained rather separate.

Previous work has primarily focused on the motivations underlying mobility choices and argued that academics can best be described as "knowledge migrants" rather than "economic migrants" (King 2002; DTI 2002; Ackers 2005). According to these studies, researchers are primarily attracted by centres of research excellence, which combine high quality infrastructure, facilities and top quality researchers. The prestige of the institution is an extra pull factor, as well as the level of autonomy academics can achieve in their work. While not the primary motivation, economic factors remain influential in academics' migration choices (Ackers and Oliver 2005). Better salaries (which also signify higher social status), increased research funding, and more generous social benefits each exert an important influence in attracting academics to a particular destination.

Among students, language acquisition and personal development are found to be important motivations for those embarking on a degree abroad but also for those engaging in credit mobility $^{2}$ (Van Mol and Timmerman 2014). The desire to discover foreign countries and cultures was also frequently cited as a motivating factor (Carlson 2014; Rosenmund et al. 2012). These cultural and experiential goals appear to sometimes outweigh academic considerations (King 2002; Balaz and Williams 2004; King and Ruiz-Gelices 2003; Findlay et al. 2012).

\footnotetext{
${ }^{2}$ Credit mobility refers to exchange students studying abroad for a semester or an entire academic year but who receive their degree from their home institutions.
} 
The extent to which individuals can enact their migration aspirations depends on their capabilities (Carling 2001; de Haas 2010), as has been extensively shown in the general migration literature. Research on academic mobility has also acknowledged factors that shape individuals' ability to respond to the motivational factors discussed above, such as their gender, family situation or social origin. Being in a couple and having children deters international mobility among students and academics, especially for women (Bauder 2012; Ackers 2001; 2005). This leads to often gender-imbalanced stocks of foreign academics: for example, in the US, 64.4 per cent of foreign scholars are men (Institute of International Education 2010). In dual-career academic couples it is the female partner who will generally sacrifice her career and follow her partner (Ackers 2001). Social origin is also found to have an impact on the likelihood to move abroad as a student: those from higher social strata make substantially more use of opportunities for studying abroad than do those from lower income families (Schnitzer and Zempel-Gino 2002; King and Ruiz-Gelices 2003). This seems however to depend on the degree of social inequality in access to higher education in origin countries (Van Mol and Timmerman 2014; Orr et al., 2008, 2011).

Furthermore, social and professional networks are found to influence mobility decisions (Bauder 2015): on the one hand, information circulated through family members, peers and supervisors' networks located abroad may increase both the aspiration and the ability to move among students and academics (Korys 2003; Millard 2005; Carlson 2014; Brooks and Waters 2010; Waters and Brooks 2011). On the other hand, the social and academic networks accumulated in situ may attach people to particular places and discourage mobility - a phenomenon that Williams et al (2004: p. 41) conceptualise as "location-specific insider advantages".

\section{b. Trajectories of academic mobility}

Most work on academic mobility takes a 'snapshot' view of international migration and focuses on the (current) motivations and factors that explain students' and academics' migration behaviour. Migration is generally analysed as being a one-time choice. The temporal sequence of events and processes that lead to migration or that make up the individual's mobility trajectory is rarely taken into account.

Yet previous research has acknowledged the importance of prior experiences of mobility for subsequent professional migration as a researcher or academic. In particular, a considerable share of scientists moving abroad for work reasons have experienced some form of student mobility, at undergraduate or postgraduate level (Ackers 2005). Two thirds of researchers moving through the Marie Curie Fellowship scheme interviewed by Van de Sande et al. (2005) had lived or studied abroad prior to their application. A similar finding was reached by Hansen (2003) with respect to EU-born researchers in the US. Inversely, a high share of those studying abroad stay on in their host countries for employment or family reasons, or remain internationally mobile by moving to a third country. Yet most work has not gone beyond a descriptive evaluation of the phenomenon. If prior student mobility is so important in determining the likelihood of working abroad as an academic, the phenomenon to be explained is less that of professional mobility than that of student migration and retention. 
In her seminal review of the literature of the scholarship on scientific mobility in the European Union, Louise Ackers argues that "any new research should curb the existing boundaries between undergraduate and other forms of academic mobility" (2005:108). Despite this call, so far the literatures on student and researcher mobility have remained separate. A promising approach for integrating the two phenomena and understanding how academics become internationally mobile is a biographical or life-history approach of academic and geographic mobility careers (Ackers 2005).

Despite an increasing recognition of the complex nature of mobility trajectories, longitudinal approaches that resituate migration events within individuals' life-course and broader sequences are still rare, particularly those focusing on academic and student mobility. In a recent exception, Sage et al. (2013) record post-graduation mobility pathways and illustrate the high levels of mobility, often unplanned, that characterise this group. The majority of studies that adopt a cross-sectional approach gloss over this high mobility and thus fail to understand the instability of the study-to-work transitions of some graduates. Faggian et al. (2007) make an innovative use of British administrative data in order to distinguish different types of sequential migration behaviour among young graduates. They reconstruct mobility trajectories by linking study- and employment-related moves and show that non-White ethnic minorities are more likely than their White counterparts to leave their home region later and to return earlier, trajectories otherwise associated with poorer employment prospects. Finally, in a rich qualitative study of German students, Carlson (2014) illustrates the importance of prior mobility experiences for studying abroad. The accumulation of such experiences constitutes a 'mobility capital' (Murphy-Lejeune 2002), an internalised disposition leading these youth to seek out new mobility opportunities (Carlson 2014).

This paper aims to contribute to this line of research by focusing on the temporal context of international academic mobility. Using quantitative methods, we reconstruct individual migration trajectories and examine the role of prior (student) migration stages on future academic mobility choices. In doing so, we bridge research on students' and academics' mobility, and argue that we cannot understand the latter without placing it within individuals' broader academic and geographical careers. We draw on the concept of path-dependency as a heuristic tool for understanding the temporal aspects of international academic mobility.

\section{c. Path-dependency, a useful angle for analysing international academic mobility}

In the following we propose the concept of 'path-dependency' as the theoretical framework for studying the mobility trajectories of academics. The initial idea of this concept was that a small initial advantage or a few minor random shocks along the way can affect the course of history (David 1985). In general, path-dependence implies that a current or future state or outcome of a process depends on its history, which in turns depends on the sequence of previous states, decisions and actions made by agents and resulting outcomes, and not only on contemporary conditions and states of the environment. Previous investments and decisions constrain future behaviour, whether of governments, firms or individuals (Bercovitz 
et al., 1996, Pierson 2000). ${ }^{3}$ A path-dependent process can be caused by increasing returns or positive externalities, which imply that the more often a certain decision is made or a certain action is taken, the greater are the respective benefits in the future. But also negative externalities caused by any form of constraint (financial, spatial, time, or even cognitive) can create path-dependency. Positive and negative externalities can change incentives, and incentives are important drivers in human decision making, for instance in the case of professional career development. Past decisions or actions that influence the way in which people respond in the future create positive or negative externalities for later decisions (Page 2006). A path-dependent process is self-reinforcing, which suggest that making a certain decision or taking a certain action establishes a set of forces or structures that facilitate a choice to be sustained in future decisions.

Path-dependent mobility behaviour can also be explained by an underlying status quo bias by which people have a strong preference for the context and situation in which they currently live (Samuelson and Zeckhauser 1988). Transition costs make moving away from the status quo less attractive, predominantly if these transition costs exceed the efficiency gains associated with the status quo. These costs are related to direct financial, socioeconomic or psychological costs of migration but include also transaction costs associated with collecting information and reducing uncertainty (Czaika 2015). Thaler (1980) describes another behavioural 'anomaly': the endowment effect, by which individuals value what they have more highly than what they could have, even if the latter carries a smaller risk of failure. This idea is closely related to the concept of sunk costs, which are costs incurred due to past investments in non-transferable skills and knowledge such as language, education, or social and professional networks. The more an individual has invested in the 'status quo location', the less likely is a subsequent self-determined shift of status and context to elsewhere. That implies that the longer an individual has spent in a certain job, profession, institution, or country, the less likely is that person to seek a contextual change - even if it would be objectively beneficial (Czaika 2015). Thus, path-dependency implies a period of 'immobility' which may be longer than the 'optimal' (migration) duration might suggest (e.g. Cassarino 2004, Dustmann 2003). Evolving academic careers can get locked into given paths of personal or academic development, excluding a host of other, perhaps more efficient or desirable, options. As a consequence, later adjustments or corrections towards perhaps more preferred ('superior') outcomes are often ruled out. Basically, the exclusion of alternatives drives a path-dependent process.

An individual path-dependent process such as the development of an academic career and mobility trajectory is integrated into a collective path-dependent process of an academic mobility system. At the meso-level, positive feedback relating to a certain action or choice creates positive externalities when that same choice is made by other people. Here, lock-in mechanisms imply that a certain (career) step or action becomes better than any alternative because a sufficient number of people have already made that step. In a path-dependent

\footnotetext{
${ }^{3}$ Theoretical, historical, and empirical studies of path dependence cover topics ranging from the selection of institutions, the formation of government policies, the choice of technologies, the location of cities, to the formation of languages and law (Page 2006).
} 
process such as academic career development, behavioural routines, social connections, or cognitive structures are built up around an institution (Page 2006). This is the consequence of a 'localized nature of learning' (Baláz and Williams 2007: 39) where individual learning about opportunities and constraints is concentrated in and around present and previous locations and activities. This activity- and place-specific learning from peers conditions future career trajectories and mobilities (Baláz and Williams 2007).

Formalised in a model of path-dependency in individual academic career and mobility trajectories, the probability of choosing location $X=\{1,2, \ldots, D\}$ in period $t$ as the destination of the next career step in $t+1$ is given by:

$$
\operatorname{Pr}\left(X_{t+1}\right)=H_{t}\left(h\left(X_{t}\right), s_{t}\right),
$$

where $s_{t}$ represents the state or environment of a mobility decision maker including for example the information available about opportunities or constraints, or other exogenous factors in a given period t. $h\left(X_{t}\right)$ captures the individual trajectory of career steps and respective locations $X_{t}$ and all other historical factors until the current period $t$. The dynamic function $H_{t}$ transforms the current state and history into a probability distribution for the next career step. This path-dependent process is non-deterministic but stochastic and biased toward past decisions. That is, certain outcomes are understood to be more likely than others, but none of these are necessarily 'optimal'. In this sense, although processes of career development are cumulative and path-dependent, they can also be interrupted by unforeseen factors or events (Page 2006). Furthermore, this dynamic process generates increasing returns (or, positive externalities) if an outcome of any type in period $t$ increases the probability of generating the same or a similar outcome in the next period $t+1$.

A refinement of this general model may distinguish between early and recent pathdependency which represent different weights assigned to respective historical periods. A career process is early path-dependent if the choice of a future career step depends mostly upon the history up to a certain period in the past. A recent path-dependent process, on contrary, puts more emphasis on the outcomes and opportunities in the more recent past, i.e. outcomes long ago such as place of birth, schooling, etc. may be irrelevant for future academic career steps. We may assume that academic careers are likely to reflect a more recent path-dependency, for example, having obtained a $\mathrm{PhD}$ abroad should be more influential in the likelihood to take up a post-doc abroad than having obtained one's bachelor's degree abroad.

Both the structure of opportunities and constraints in the global academic labour market and individual aspirations may explain why academic careers are expected to be geographically path-dependent. The Indian higher education system being still at the periphery of international knowledge systems, those with Indian-only degrees may find it increasingly difficult to move closer to the 'global scientific core'. At the same time, as they climb the academic ladder from $\mathrm{BA}$, to $\mathrm{MA}, \mathrm{PhD}$ and beyond, individuals also form families and social attachments which decreases aspirations to move abroad, and thus, keeps them in their place. Conversely, those who already moved closer to the 'scientific core countries' during their years of education, have less academic incentives to return to the periphery (although they 
might have the ability to do so) and have in their turn developed social and professional attachments in their host countries.

However, as discussed above, path-dependency is not a deterministic process, as it may be influenced by a series of contextual and individual factors. First - and the next section will discuss this in more detail - the Indian higher-education landscape has been undergoing substantial changes in recent years. International experience is increasingly required in order to get a position in top institutions such as the highly regarded Indian Institutes of Technology, national universities or research institutes. At the same time, getting a $\mathrm{PhD}$, mostly in natural sciences and engineering, from these highly selective institutions is well regarded by foreign universities. This changing structure of opportunities and constraints means that a growing number of capable students will prefer to stay in India for their $\mathrm{PhD}$, but will be confronted with the need to get out of India for a post-doc if they want to find a good job within the Indian academic and research system. These recent changes should therefore reduce the geographical path-dependency of Indian research careers.

Second, we expect these dynamics to be especially visible within certain disciplines, such as the natural sciences, mathematics or engineering, in which India has invested substantially in recent years. In contrast, those who want to engage in social science or humanities careers have both fewer opportunities to study for a high-quality $\mathrm{PhD}$ in India and fewer employment opportunities afterwards. For them, international careers may still be a better option altogether.

Besides these contextual dynamics, individual-level factors may also moderate the weight of past mobility decisions on future migration trajectories. First, outstanding individuals may be more likely to gain admission to universities at the global scientific core - in North America or the UK - even with an all-Indian education. They may thus be more likely to 'break the path' set out in front of them if they wish to do so. Second, individuals from privileged backgrounds, for instance those with highly educated parents, may also have better cultural and linguistic resources than those from less privileged backgrounds, which may gain them admission abroad in the absence of prior foreign qualifications. Last, previous research has shown that female students and academics are less likely than men to be internationally mobile. We may thus expect women to be disadvantaged in the accumulation of international experience over their academic trajectory, especially as family considerations become more important over the course of a life cycle. Thus, we hypothesise that men are more likely than women to break a domestic academic career path, and be more likely to move abroad for the first time at later stages of their careers.

\section{Indian higher education system and academic careers}

The Indian higher education system, the third largest academic system after China and the US, has expanded rapidly over recent decades, in particular in recent years. This expansion in academic capacity came partly at expense of quality, however. It is estimated that 95 per cent of all India-based academics work in an environment that is significantly below international standards (Jayaram 2003). Like most higher education systems in the developing world, the 
Indian academic system is also characterised (and overwhelmed) by a massification of higher education, with ever increasing student enrolments and high teaching loads. A privatisation of the higher education sector as a consequence of internationally imposed structural adjustment programmes in the early 1990s, in combination with an increasing marketisation in which academics are expected to undertake some extra entrepreneurial activities, have left the academic profession in a substandard state (Altbach 2011).

Indian academics, like most scholars working in developing countries, tend to come from the more privileged segments of their societies, that is, from well-educated, mostly urban, families. Interestingly, academics usually do not come from 'elite families', mainly due to comparatively low salaries and the limited prestige and social recognition of the academic profession (Altbach 2011). This is also reflected by a relatively low interest in researchoriented courses among students as only one percent of students enrol in a $\mathrm{PhD}$ programme at an Indian higher education institution (FICCI 2014). For instance, India produces only 400 $\mathrm{PhDs}$ in engineering a year, despite nearly 350,000 engineering students graduating every year (cf. Unni 2016, based on figures from the Federation of Indian Chambers of Commerce \& Industry).

The low domestic supply of highly qualified doctorate holders may be largely the consequence of limited high-quality training and career opportunities in India. Teaching and research usually do not go together as the higher education sector is divided into teachingfocused universities and colleges, making up about three quarters of all institutions (Krishna 2016) on the one hand, and research-based universities and institutions on the other, hosting less than 3\% of students (FICCI 2014). Furthermore, particularly in the STEM fields, research also stems from the R\&D laboratories of private companies, which employed about a quarter of the scientific and technical human resources in 2010, as well as from the public research system - national research centres based at state agencies or large public sector enterprises -, home to $61 \%$ of the R\&D personnel in the country (Krishna 2016).

Chronically under-funded, Indian universities struggle to attract and retain top scholars, which results in a lack of qualified research manpower. Even at the reputable Indian Institutes of Technology (IITs), a large number of faculty positions often remain vacant for a long period of time, leading to high (and increasing) student-faculty ratios. As a consequence of these structural deficiencies in the higher education sector, India has the largest diaspora of worldwide researchers, with 40 per cent of Indian-born researchers working overseas and 75 per cent of its scientists moving to the US. About 25,000 IIT-alumni have settled in the US since 1953 (Friedman 2006). Return rates are relatively low with only 5 per cent of Indians who go to the US to earn a doctorate returning home after graduation (Chang and Milan 2012).

India aims to reverse this 'brain drain' by a rapid expansion of its higher education infrastructure. Recently the Indian government allowed foreign universities to set up nonprofit campuses and to offer foreign degrees, no longer requiring them to undertake a jointventure with a local education provider. Additionally, India's elite institutions (IITs and IIMs) have put in place flexible recruitment policies, more generous research grants and industry-academic collaborations in order to attract back researchers. 
Partly as a consequence of these policies, Indian universities have been able to attract an increasing number of researchers back home (Sabharvwal and Varma 2016). Furthermore, US-educated scientists and engineers increasingly returned to India to set up new start-ups, thus contributing to technological innovation with potential spill overs for the academic sector (Saxenian 2007). However, Indian universities still do not make it to the top of global university rankings. In the 2014/15 Times Higher Education ranking, only four Indian institutions appeared in the global top 400, none in the top 200. This demonstrates that the Indian higher education sector is not (yet) a competitive player on the global academic market, and also on the rapidly emerging Asian knowledge market. Most Indian higher education institutions are still struggling to retain or incentivise the return of prospective Indian faculty.

The following analysis is dedicated to exploring in greater detail international career and mobility paths of Indian-born academics with a particular focus on the timing and pathdependency of these academic careers.

\section{Data and methodology}

In order to study the drivers of academic mobility among Indian researchers, we use data from the Global Survey of Researchers, an online survey we conducted between February and July 2014. We adopted a multi-sited data collection strategy by surveying both mobile researchers currently living in different countries around the globe, as well as researchers based in India who never lived abroad or who had returned to India. Since researchers generally have access to IT facilities, it was possible to use web-based survey methods to reach them, thereby enabling us to interview Indian academics in a large number of countries. We surveyed active researchers, who had published at least one article, research paper, conference proceeding or book indexed in Thomson Reuter's Web of Knowledge database in the last four years, across all disciplines. Thus, our survey is not only focused on academics i.e. those who hold an academic position in a higher education institution - but targets all those publishing academic research, whether they are employed in a public or private research institute, a university, still studying, retired or unemployed. In order to target Indian researchers we adopted a name-based sampling strategy. Among this population, we selected those with an Indian surname ${ }^{4}$ and contacted all those corresponding authors for whom an email address was present in the database. Our target population thus comprises all researchers who published at least one article in the last four years in a journal indexed by Thomson Reuters, who had an Indian surname according to our definition, and for whom an email address was recorded.

Researchers were invited to fill our questionnaire, which collects information on their educational and professional trajectories, including the locations (country and institution) for each major degree or work transition (BA, MA, $\mathrm{PhD}$, first job, current job) as well as the

\footnotetext{
${ }^{4}$ In order to determine whether a name was Indian or not, we compared its frequency within the pool of Indianbased researchers to their frequency in the worldwide pool of researchers (based on those appearing in the Thomson Reuters Web of Knowledge database). See Toma et al. (2016) for more details on the sampling strategy
} 
reasons for choosing these locations, among other aspects ${ }^{5}$. As the survey was implemented online, a full retrospective design was not possible because of time constraints. While we therefore do not have our respondents' complete educational and professional trajectories, we can follow their geographic paths across the five key stages of their careers. We can thus take into account the sequencing of moves and adopt a holistic view of geographic migration, going thus beyond what was done by other surveys on academic mobility that are entirely cross-sectional in their design.

We used the platform Qualtrics to administer the questionnaire. The language of the survey and of the invitation letter was English. Each researcher was emailed at most three times (of which two were reminders) during a period of three months. Around 17,000 researchers started our survey, amounting to a total response rate of 12.8 per cent (excluding bounced emails). A recent feature of the Qualtrics platform allows us to see the number of emails that were opened, and thus the number of targeted researchers who actually saw our invitation. Only about 30 per cent of them opened the email invitation; it is likely that a high number of unopened emails were trapped by spam filters. The total response rate of the opened emails is 46.3 per cent. In this paper, we use only complete answers (i.e. respondents who got to the last question of the survey and submitted their responses) of Indian-born researchers who have obtained their $\mathrm{PhD}$ degree, which gives us a sample size of almost 4,600 individuals. Men and researchers in natural sciences and engineering make up the largest part of our sample, but in the absence of other data on Indian academics worldwide it is difficult to know to what extent these groups are over- or under-represented. Table A-1, in the Appendix, presents descriptive statistics for our dependent and independent variables. ${ }^{6}$

We employ two types of methods to analyse our data. First, we use sequence analysis to visualize the level and the timing of geographic mobility within educational and professional trajectories. Sequence analysis is most adequate at capturing the broader sequencing of (mobility) events and the unfolding of the trajectories of interest - in our case the geographic mobility paths of academics (Billari and Piccareta 2005). Unlike its cousin event-history analysis, which seeks to explain one-time events, sequence analysis allows the researchers to adopt a holistic perspective of the process of interest (Billari 2001).

We further compare researchers of different cohorts, disciplines, social origins and end of high school performance in their mobility trajectories. We distinguish three cohorts: the youngest (those aged 35 or under at the time of the survey), the middle cohort (those between 36 and 50) and the oldest cohort (those 51 or over). The discipline variable is constructed based on the discipline of the respondents' $\mathrm{PhD}$ degree and was regrouped in four categories 1) social sciences, humanities, business and health 2) natural sciences, mathematics, computing, statistics 3) engineering, and 4) other. We proxy social background by highest parental level of education, reported both for fathers and mothers. The variables have four

\footnotetext{
${ }^{5}$ See the project website (https://www.imi.ox.ac.uk/completed-projects/drivers-and-dynamics-of-high-skilledmigration) for the full questionnaire.

${ }^{6} \mathrm{We}$ also contacted a subsample of the respondents and conducted around 45 follow-up qualitative interviews with them through Skype. The findings of this qualitative component of our project are reported elsewhere (Toma et al 2015, Toma and Villares-Varela 2015).
} 
categories: 1) primary level or less 2) secondary level 3) bachelor's degree 4) master's degree or more.

Finally, we attempt to measure individual performance by asking respondents to report their end of high school national examination grades, a key exam that greatly impacts upon students' chances of entering their preferred university. The advantage of this early measure of performance is that it pre-dates all career transitions that are of interest in our analysis, while likely being correlated with later exam scores or other performance indicators. However, this measure may not be very accurate given, on the one hand, the inevitable retrospective bias involved and, on the other hand, the regional and temporal variability in the way scores are recorded. To minimize the latter limitation, we offered respondents the possibility of recording their answer by choosing from five different scales (the ones most frequently used in India). We regrouped the values of the variable in four categories of scores 1) good, average or below (70 per cent or lower) 2) very good (71 to 80 per cent) 3) superior (81 to 90 per cent) and 4) excellent (over 91 per cent).

Second, we conduct logistic regression analysis to model the mobility decisions that researchers took at different points in their educational and professional careers: whether they went abroad for their BA, MA, PhD, for their first job after their highest degree, for their current job (if different from their first). Multinomial logistic regression was also used in order to further distinguish between different geographical destinations (i.e. India, Other Asia, North America, UK, Other Europe, Rest of the World) at three key moments of the respondents' careers: their $\mathrm{PhD}$, their first and their current job.

\section{Dynamics of Indian academic mobility: some findings}

\section{a. Typologies of trajectories}

Cross-sectional descriptive statistics are limited since they do not take into account the sequencing of events within an individual trajectory, which is of particular interest for our analysis. Using sequence analysis, we illustrate Indian researchers' trajectories over time and space, and across different groups. More precisely, the figures 1 to 5 below display the geographical locations of our respondents' $\mathrm{BA}, \mathrm{MA}, \mathrm{PhD}$ degrees and of their first and current jobs, in this order. Each horizontal line represents an individual trajectory made up of these five steps, and six different geographical areas are distinguished (India, Other Asia, North America, UK, Other Europe, Rest of the World).

Figure 1 shows that the vast majority of Indian-born researchers surveyed did their BA degree in India, with a small minority (around 3 per cent) studying abroad, mostly in North America, and particularly in the US (Figure 1 and Table O-1). ${ }^{7}$

\section{****Figure 1 about here ${ }^{* * *}$}

\footnotetext{
${ }^{7}$ A-enumerated tables are in the appendix of this paper, whereas $\mathrm{O}$-enumerated tables can be found in the online supplement.
} 
The share of those who study abroad increases at the master's and even more so at the doctoral level, comprising 12 per cent and 24 per cent of our sample respectively. While most of those who study abroad end up working abroad (though not necessarily in the same country), around a third of our respondents take up a first job (post-doc) outside of India after an all-Indian education. This mobility is less likely to intervene at a later-job stage, though it is not completely absent either (concerning 13 per cent of respondents).

In all, around 45 per cent of Indian researchers were abroad for at least one of their major degrees or for a professional experience. In terms of their region of destination, those who study abroad mostly choose North America, with the UK (13 per cent) and other European countries (11 per cent) claiming a sizeable share at the $\mathrm{PhD}$ level. However, destinations become more diverse at the level of the first or the current job abroad, with the share of those choosing a North American country decreasing from $67 \%$ at the $\mathrm{PhD}$ level to $53 \%$ for their current job. The share of other European countries is greatest at the post-doc stage (16\%) whereas other Asian destination are more frequent at the level of the current job (19\%) (Table O-1).

These geographical patterns as well as the timing of migration seem to have changed over time, if we compare the different generations of Indian academics, as was done in Figure 2. Furthermore, Table O-2A and O-2B report relative regional frequencies as well as the top 10 trajectories by cohort group. The oldest cohorts - researchers who were over 50 at the time of the survey - were predominantly choosing North America and the UK in terms of study and work destinations, whereas other European and Asian destinations are much more frequent among the youngest generation (those under 36 years of age at the time of the survey). Furthermore, while a fifth of the oldest cohort members (those over 51) moved abroad directly for a professional opportunity, without having first studied abroad, this trend became much more frequent in the younger cohorts, concerning more than a third of those under 50 (Table O-2A). In Figure 2, this is apparent in the much larger increase in those located abroad between the $\mathrm{PhD}$ and the first job stages. Moving to another European or moving to another Asian country for a post-doc after an all-Indian education before returning to India are two of the top ten trajectories of those under 50 but not among the oldest cohort (Table O-2B).

****Figure 2 about here ${ }^{* * * *}$

Figure 3 (and Table O-3A and O-3B) demonstrates that patterns of international mobility differ greatly by scientific discipline. Those engaged in the social sciences and humanities, who make up only a small share of our population, appear much more than those in other disciplines to move abroad for their studies, especially at the doctoral level (around 45 per cent). In comparison, less than a fifth of those in natural sciences (as well as mathematics or computer science) go abroad for their PhD degrees. Instead, a much larger share of the latter move directly for a first job abroad (44\% compared to $11 \%$ among social scientists), followed, in many cases, by a return to India. This is also illustrated in Table O-3B: the 
second most frequent trajectory among social scientists is moving to North America for their master's degree and remaining there up to their current job (8\% compared to $3 \%$ among natural scientists). In contrast, the second most frequent trajectory among natural scientists is completing their education in India, moving to North America for a post-doc, and returning to India for their current job (5\%). Those in engineering fall somewhere in between, as their likelihood of studying abroad is higher than for the natural scientists, but they are less likely to work abroad as academics, especially if they have not first studied abroad.

****Figure 3 about here ${ }^{* * * *}$

There are other aspects of researchers' backgrounds that appear to shape the level of international mobility they experience, the timing of the moves in their trajectories as well as the destinations they choose. Figure 4 (and Tables O-4A and O-4B) illustrate the influence of fathers' level of education, which is arguably correlated with their social class. Those researchers whose father has a university-level degree appear much more likely to study or work abroad, to move earlier ${ }^{8}$, and to go to the 'traditional' destinations in North America and the $\mathrm{UK}^{9}$. These patterns are even more pronounced for those whose fathers have a master's or $\mathrm{PhD}$ level degree compared to those who only have a bachelor's degree. Confirming these trends, Table $\mathrm{O}-4 \mathrm{~B}$ shows that none of the top ten trajectories of respondents with $\mathrm{MA}$ - or $\mathrm{PhD}$ - educated fathers include a move abroad beyond North America.

\section{****Figure 4 about here ${ }^{* * * *}$}

Figure 5 (and Tables O-5A and O-5B) compares researchers' trajectories by the self-reported final grade at the end of high school national examination ${ }^{10}$. Those who reported having obtained the highest ('excellent') scores at the end of high school are also those who leave India in greater numbers at all career stages, but in particular at early stages, and who mostly choose the US and the UK as destinations. Only about a quarter (26.9 per cent) of those with top high school marks never leave India at any stage of their academic career, compared to two thirds of those reporting good or lower scores (Table 0-5B)

****Figure 5 about here ${ }^{* * * *}$

\footnotetext{
${ }^{8} 6 \%$ of those whose father has an MA degree or above first moved for their Bachelor's degree, compared to $2.2 \%$ of those whose father has primary level education or less.

${ }^{9}$ There is a strong linear gradient in the share of those doing their PhD degree in North America: from $76 \%$ among those with MA-educated fathers down to 50\% among those whose fathers had a primary-level education or less.

${ }^{10}$ Admittedly, this measure may not be very accurate given, on the one hand, the inevitable retrospective bias involved and, on the other hand, its great regional and temporal variability in the way scores are recorded. To minimise the latter limitation, we offered respondents the possibility of recording their answer by choosing from five different scales (the ones most frequently used in India).
} 
In sum, the above figures illustrate the prevalence of international mobility among Indianborn researchers, but also its path-dependent character. Moving abroad for studies or work at an earlier stage shapes subsequent trajectories and future destinations. However, the figures also show that the observed patterns vary greatly by cohort, by discipline and by researchers' social origin and high school performance, which is further investigated in the next section.

\section{b. Drivers and dynamics of international academic mobility}

The previous descriptive analysis of career trajectories revealed some path-dependent patterns in individual career trajectories of Indian-born academics. The following analysis will explore these path-dependencies more systematically by assessing their importance in comparison to other drivers of international academic mobility. Table 1 displays estimates (marginal effects) of the probability of moving abroad at the five different stages of an academic career that were also considered in the previous section. Besides the role of previous international career steps (i.e. BA, MA, PhD degrees and first job, respectively), we test various individual-specific factors such as discipline, cohort, gender, parents' educational background and place of birth in addition to our assessment of path-dependency in international career trajectories.

By comparing marginal effects of discipline on the probability for international academic mobility across all five career steps (models 1-8), we confirm that social scientists (reference category) tend to move abroad much earlier than natural scientists. The latter move abroad on average to a larger extent than social scientists only after having acquired their $\mathrm{PhD}$, in order to seek a post-doc position abroad. In addition, for later positions after the post-doc years, social scientists have a higher probability of moving or staying abroad than colleagues in the so-called 'hard sciences'. We also identify some cohort effects, which show that international mobility at various stages of an academic career has become more common than it used to be for earlier generations. This trend, however, is more salient for the employment stages where younger cohorts have an around 5 to 10 per cent higher probability of working abroad than older cohorts. For the study years, the effects across cohorts are rather mixed. For instance, older cohorts had a slightly higher probability of doing their bachelor's degree or a $\mathrm{PhD}$ abroad than younger cohorts. This implies that younger cohorts of Indian-born academics seem to move abroad slightly later than older colleagues used to do.

The gender composition in our sample, which comprises one-quarter female academics, reflects a well-established fact that females are generally underrepresented in academia, and particularly in the hard sciences (which make up three quarters of our population). Interestingly, female academics are even more underrepresented in international mobility at various stages of an academic career. While female and male academics have similar propensities for starting their academic trajectory with an international BA, male academics have a significantly higher probability of seeking both graduate education and a post-doc position abroad compared to their female colleagues. Only at later stages of academic employment, i.e. after the post-doc, do we no longer find such a gender bias in international academic mobility. 
We further examine the influence of parent's educational background on academic mobility trajectories. We find that parents' educational attainments only influence study abroad decisions, but do not significantly influence decisions regarding academic employment, once the degree location is taken into account. Interestingly, the decision to go abroad for an international degree at master's or $\mathrm{PhD}$ level is more influenced by the tertiary education of the mother than that of the father; whereas international mobility at the bachelor's level is more likely if fathers are tertiary- educated. Estimates of the place of birth variable show that academics who grew up in rather remote rural areas have a lower probability of integrating international spells into their career. This negative effect exists for all career stages but is only statistically significant at educational stages.

Evidence on the relative importance of parents' education on offspring's educational attainment is well-established in the literature (Duncan and Duncan 1968; Bourdieu and Passeron 1964). This study brings fresh evidence that having more highly-educated parents increases one's chances of engaging in an international academic career: first, by directly increasing the likelihood of studying abroad; then, by indirectly raising the chances of staying abroad for an academic employment. However, although parents' education seems to matter in future career trajectories, its relevance to this historical path-dependency is relatively minor compared to more recent factors in individual academic career paths, as estimates on previous career steps show.

Models 1 and 2 report estimates of the probability of moving internationally for acquiring the bachelor's degree. The marginal effect of having graduated from high school outside India, despite being born in India, increases significantly the probability (by 43 per cent) of staying abroad for one's bachelor's degree.

For those who graduated from an Indian high school (models 2-8), the self-reported scores obtained at the end of high school national examination seem to matter in predicting future international study mobility. Top students with excellent marks have about a three per cent higher probability of moving abroad for a BA than those with 'only' good marks. School performance seems to matter even more for seeking advanced international degrees at master's or PhD level. Here, excellent marks at the end of high school examination predict a 15 to 20 per cent higher likelihood of pursuing an international degree than that of students with 'only' good results. Interestingly, school marks remain an early indicator for later international mobility for academic employment, even though to a lesser extent.

****Table 1 about here ${ }^{* * * *}$

These early signs of an international academic career are reinforced by later educational steps such as an international master's or $\mathrm{PhD}$. Model 3 for instance shows that a previous international BA degree increases the probability of staying abroad for a master's degree by about 36 per cent compared to students without previous international experience. This effect of a previous international degree on the probability of a later international mobility is even 
stronger at the $\mathrm{PhD}$ level. Students who have obtained their master's degree abroad are 64 per cent more likely to also do their $\mathrm{PhD}$ abroad (model 4). This high probability can partly be explained by the fact that master's programmes are often integrated into or are the first step in a $\mathrm{PhD}$ programme. When it comes to international academic employment, students with an international $\mathrm{PhD}$ are about 54 per cent more likely to stay abroad for their first job, which is usually a researcher or post-doc position. Model 6 includes not only the previous $\mathrm{PhD}$ but also the master's degree as predictors of seeking a first job outside India. Including the master's stage diminishes only marginally the predictive power of an international $\mathrm{PhD}$, whereas an international master's degree increases by 15 per cent the probability of first academic employment abroad. This suggests that later career steps are still driven by international experience at early career stages, and that there is a cumulative effect of previous mobility experiences. Models 7 and 8 estimate the probability of international employment at the time of the survey, if that employment is different to their first job ${ }^{11}$. This employment may be more or less senior depending the cohort, which is controlled for. Interestingly, the decision to seek international employment at later stages of an academic career is still significantly driven by the location of the $\mathrm{PhD}$ degree, but to a lesser extent than first employment. Holding a foreign PhD degree increases the probability of being currently employed outside India by 18 to 22 per cent, which is only slightly lower than the marginal effects of an international post-doc. Model 8 estimates the effect of all career stages for which we have data on current employment location, and finds an almost 'linear' decrease in the effect of previous international experiences on a later academic position, with earlier experiences being less influential than later ones. While an international first academic employment increases the probability of working abroad at the time of the survey by about 24 per cent, an international $\mathrm{PhD}$ only contributes about 18 per cent, while an international master's adds another 9 per cent and an international bachelor's contributes only an insignificant 6 per cent. Furthermore, end of high school scores no longer matter. These results suggest a strong element of so-called recent path-dependency, in which more historical stages in international academic career trajectories reduce in importance but are still relevant.

Results reported in Table 2, which are based on the same core model as the specifications in Table 1, further explore the role of the previous two career steps on the probability of moving abroad for a $\mathrm{PhD}$ (Model 1), the first job (Model 2), and a later academic employment (Model 3), by focusing on the sequencing of international experience stages. Estimates on Model 1 show that the probability of moving or staying abroad to pursue a $\mathrm{PhD}$ is significantly higher if either a BA or a MA degree were attained abroad. If both degrees were acquired abroad then almost certainly the PhD is also pursued abroad. However, in the case that either the master's or the undergraduate (bachelor) degree have been received abroad, but not both degrees, then the international Master's degree has slightly stronger predictive power for an international $\mathrm{PhD}$ degree.

\footnotetext{
${ }^{11}$ Only a part of our respondents had two or more jobs after their highest degree, which explains the decrease in sample sizes between Model 6 and 7.
} 
Model 2 shows that the probability of staying abroad for the first academic job after an international master's and $\mathrm{PhD}$ is 63 per cent higher than if both degrees were obtained in India. An international $\mathrm{PhD}$ is hereby far more important in explaining first international employment than having obtained only the master's degree abroad. Students who have only completed their PhD abroad but not their master's are 50 per cent more likely to have a first international employment (i.e. about 13 per cent less likely than in the case that both degrees were obtained abroad) than those who did neither of these degrees abroad. Interestingly enough, if Indian students return after their international master's for a 'domestic' $\mathrm{PhD}$ the probability of moving abroad is not significantly different from the case in which all degrees were done in India. That is, pursuing a $\mathrm{PhD}$ back home absorbs the value of international experience gained by an international MA and diminishes the prospects for future international employment. On the other hand, it may also reflect a strong personal preference attached to living in India and therefore a previous decision to re-settle there more permanently.

\section{***Table 2 about here $\mathrm{F}^{* * *}$}

A similar pattern in the sequencing of international spells exists for later employment outside India. The strongest effect on the likelihood of seeking international academic employment at later stages of the academic career is highest if both the $\mathrm{PhD}$ and post-doc were done abroad. This trajectory predicts an approximately 50 per cent higher probability for a later job abroad than if both previous career steps were completed in India. If only one of the two career stages were completed abroad, then the international post-doc has a significantly higher predictive power for pursuing later academic employment than in the case where an academic returns home after having obtained the $\mathrm{PhD}$ abroad. These results show that the strongest predictor for the location of the next step in an international academic career is the current location. However, preceding career stages also matter, and which result in path-dependent academic career trajectories. This implies that academics without any current or previous international experience are also unlikely to move abroad at a later stage. International academic careers start early and the longer academics stay abroad the less likely becomes their return. If academics return after a certain period abroad, future (re-) migration for employment is unlikely.

So far, we have not differentiated between international destinations. Table 3 displays marginal effects of previous career steps (degrees) on the probability of staying in India or moving to a certain region of destination for a $\mathrm{PhD}$ (Panel A), the first academic job (Panel B), and a later academic employment (Panel C). We run this multinomial regression twice, first without differentiating between the place of the previous career step, and second, by distinguishing between the three major Anglo-Saxon destinations (the US, Canada and the UK) and other international destinations outside India (Rest of World).

Estimates on the role of an international MA degree on the destination choice for a $\mathrm{PhD}$ (Panel A) show that the probability of pursuing a $\mathrm{PhD}$ at an Indian higher education institution after an international MA is significantly lower than choosing an international 
$\mathrm{PhD}$, no matter whether the MA was obtain from a North American, British or another university outside India (1a-6a). On the other hand, international experience at the master's level increases significantly the probability of pursuing the $\mathrm{PhD}$ at a North American institution (model 1c). However, it would be an illusion to believe that any international MA would increase the chances of obtaining a North American PhD. Master's degrees acquired at North American or British universities increase the average probability of a $\mathrm{PhD}$ at a North American institution by 62 per cent compared to a master's degree from an Indian university, whereas master's degrees from other universities outside India do not significantly increase chances of obtaining a North American PhD (Model 3b). British doctoral programmes, on the other hand, seem to be able and willing to attract not only master's degree holders from North American universities, but also from other universities outside India.

Thus, there appears to be a strong path-dependency in the entrance to North American $\mathrm{PhD}$ programmes, where a master's degree from an Anglo-Saxon university seems essential. In comparison, British doctoral programmes seem to recruit more widely. This pattern seems to reflect, at least partially, tighter selection processes of North American and, to a lesser extent, British universities. Top students with excellent school marks have a significantly higher probability of selecting or being selected by a North American or British university for their $\mathrm{PhD}$ than students with only average grades. Selection patterns of universities in other countries outside India seem not significantly different from those of Indian institutions in terms of students' school performance.

\section{****Table 3 about here ${ }^{* * * *}$}

Interestingly, a similar geographical path-dependency exists also for academic mobility at the post-doc level (Panel B). Holders of a North American PhD are 59 per cent more likely to stay for their post-doc years in the North American market than PhD holders from an Indian institution. This difference in average probability is significantly smaller (only 8 per cent) for academics who have obtained their $\mathrm{PhD}$ from a British university. What is true for the $\mathrm{PhD}$ level also holds for the post-doc level: academics hardly return to India after they have obtained their $\mathrm{PhD}$ abroad. Instead, they seem to stay where they have obtained their $\mathrm{PhD}$. Interesting though is that the North American academic job market seems to be more open at the post-doc level than at the $\mathrm{PhD}$ level for graduates with degrees from non-North American or British universities.

For later academic jobs at a more senior level, mobility patterns seem to become a bit more diverse, or less path-dependent. However, diversification of academic career trajectories after for instance a North American post-doc is still very limited. The probability of Indian academics, who have done their post-doc in North America or the UK, to continue their academic career at another institution outside this Anglo-Saxon scientific core is not significantly different from returning back to India. In fact, return to India seems much more likely after a post-doc than after the $\mathrm{PhD}$, although return after a post-doc in North America or the UK is less likely than returning home from another higher education or research institution outside India. 
Interestingly, our results show that obtaining top high-school grades increase not only the likelihood to spend one's early academic career in North America (and Britain) for earning e.g. a PhD, but also later professional prospects, such as taking up a post-doc or a more senior academic job in North America, given the (financial) ability to do so. For all other destinations outside India, grades at the end of high school are not significant indicators of future academic career mobility.

In summary, our results so far have shown some evidence of a temporal and geographical path-dependency in academic career and mobility trajectories. Academics seem to select into international careers at a very early stage of their education and follow these paths throughout their careers. We have identified some predictors of this selection such as the educational background of parents, high-school performance, or socio-demographic background. However, under certain circumstances, an academic path-dependency can be 'broken' or moderated.

\section{d. 'Breaking the path': contextualising path-dependency}

This last section examines the conditions under which the strong weight of previous career locations on future ones is moderated. We investigate this by introducing interaction terms between some of our controls and the previous career step. Table 4 summarises our results.

****Table 4 about here $\mathrm{F}^{* * *}$

\section{Path-dependency across disciplines}

Estimated probabilities and confidence intervals show that there is no significant difference by discipline in the probability of pursuing a $\mathrm{PhD}$ abroad for those who have a prior degree (MA) from abroad. Probabilities range between 86 and 94 per cent with overlapping confidence intervals. However, among those who obtained their master's degree from India, those in the social sciences and humanities have a substantially higher probability of pursuing their $\mathrm{PhD}$ abroad than those in natural sciences. The trends are reversed at the post-doc level. Again, discipline does not appear to matter for those with a $\mathrm{PhD}$ abroad, but among those with a $\mathrm{PhD}$ degree obtained in India, graduates in natural sciences have a much larger likelihood of going abroad for a first academic employment (20 per cent compared 6 percent for social scientists).

In other words, while far from absent, the observed path-dependency at the post-doc stage is lower within the natural sciences. We can relate this to recent changes in the higher education landscape in India, as opportunities to do a high-quality $\mathrm{PhD}$ in hard sciences at a good institution in India have increased, whereas the same cannot necessarily be said regarding doctoral programmes in the social sciences. This is reflected by the significantly higher probability of social scientists going abroad for a $\mathrm{PhD}$ degree without prior international degree than for other disciplines. On the other hand, as discussed above, international experience is highly valued by prestigious Indian institutions when they recruit their academic staff, which creates a strong incentive for those with Indian PhDs to do a post-doc abroad. These findings are closely echoed in our qualitative interviews with physicists, 
chemists, mathematicians and other scientists who preferred to stay in India for their PhD in prestigious institutions such as the IITs, but felt it necessary for their career progression in India to obtain some international exposure. This most often took the form of a 3-4 year postdoc - no longer, since that would presumably be detrimental to successful reintegration preferably in an Anglo-Saxon country such as the US, the UK or Canada. Thus, PhD graduates in hard sciences from India have a relatively more highly-valued $\mathrm{PhD}$ degree on the international job market which enables them to look for a first job abroad. These constraints and opportunities may explain their different geographical mobility paths compared to their peers in the social sciences and humanities. The case of engineering $\mathrm{PhD}$ graduates is slightly puzzling as we expected them to experience a similar structure of incentives as those in natural sciences; instead, their migration chances in the absence of a PhD abroad resemble more those of the social scientists.

Conversely, those in the natural sciences have the lowest likelihood to be employed abroad at the time of the survey if their first employment was abroad. ${ }^{12}$ In other words, compared to the other disciplines, they are the most likely to return to India after a post-doctoral job outside, followed by those in engineering and the other disciplines. The probability of remaining abroad is significantly higher for the social scientists, which, again, presumably reflects the lower employment opportunities in these fields back in India.

\section{Path-dependency across generations}

The importance of previous career steps has also changed over time. The younger and particularly the middle cohorts were less likely to study abroad for their $\mathrm{PhD}$ in the absence of an international master's degree than the oldest cohort (over 51 years old). In contrast, the probability to remain abroad for the $\mathrm{PhD}$ once you have an MA degree from outside India has not significantly changed across generations.

The transition from $\mathrm{PhD}$ to the first academic employment evolved differently: among both foreign and Indian $\mathrm{PhD}$ graduates, the likelihood of going or remaining abroad for a post-doc has increased among the younger generations. The probability of moving abroad for a postdoc after an Indian $\mathrm{PhD}$ is about 20 per cent for the youngest cohorts compared to only 9 per cent for the oldest generation. This trend presumably reflects the increased pressure to have some cutting-edge international research exposure and experience.

\section{Gender discrepancy only for the first departure}

We also examined whether men and women have different chances and opportunities to "break the path". And indeed, we find a slight but significant discrepancy of five percentage points between women and men in their likelihood of taking up a $\mathrm{PhD}$ abroad when they do not already have an MA earned abroad. In contrast, no significant gender difference is found when both groups hold an MA degree from a non-Indian institution. Similar results are found with respect to later transitions: to a first employment as a post-doc or a later academic job. Thus, we find that women experience an initial disadvantage when making their first

\footnotetext{
${ }^{12}$ Not shown in Table 4, but full estimation results of 'later employment' are available on request from authors.
} 
international move (either for study or for work), but that once abroad they have the same probability as men of staying abroad for the next stage of their career.

\section{Individual ability: a useful resource for breaking into international career paths}

Another factor potentially moderating the geographic path-dependency is individual ability or performance. We may expect outstanding students or researchers to be more likely to "break the path", and move abroad for study or work even in the absence of a previous international degree. We examine this issue by adding interaction terms between exam scores and the location of the previous degree when estimating the likelihood of studying abroad for a $\mathrm{PhD}$ and the likelihood of taking up a first academic employment abroad, respectively. As Table 4 illustrates, school performance (final grade of high school exam) does not affect the probability of studying abroad for a PhD for those who already hold a foreign MA degree: no matter what the final school grade was, the probability of staying abroad for a $\mathrm{PhD}$ is above 90 per cent.

On the other hand, these scores significantly and quite substantially shape the propensity to do one's $\mathrm{PhD}$ abroad for students who did not obtain their MA degree abroad. Although far from compensating for the lack of an international MA degree, having obtained excellent scores significantly increases the chances of a student with an Indian MA degree to move abroad for his/her PhD (30 per cent chances compared to 7 per cent chances among those with good marks or below). Reading this finding the other way around implies that getting one's MA abroad entirely makes up for poor exam scores at the end of high school, which no longer shapes the chances of getting into an international doctoral programme. End of high school exam scores continue to shape the probability of taking up a first academic employment abroad, but in a similar way for both $\mathrm{PhD}$ graduates from abroad and from India. However, their effect is overall smaller and differences between levels are not always significant.

\section{Social origin, a limited influence}

Finally, we may expect that individuals coming from more privileged class backgrounds will be more likely to overcome the disadvantage of lacking an international degree by compensating with other resources (cultural or financial capital). However, we find only weak evidence pointing in this direction: students with an Indian MA and whose mother also has a university degree are significantly more likely to go abroad for their $\mathrm{PhD}$ than students whose mother has only a primary level education or less. However, the difference in probabilities is minor ${ }^{13}$. Social background does not affect probabilities of joining a foreign $\mathrm{PhD}$ programme for those who already have a foreign MA degree.

Similar results are found when taking into account the father's education (not reported). Parental education has no significant effect on later transitions, from a $\mathrm{PhD}$ to a first employment as a post-doc, or from the first to later employment. Thus, it seems that the main advantage of those coming from privileged backgrounds in terms of parental education is that

\footnotetext{
${ }^{13} 17$ per cent for the former compared to 11 per cent for the latter.
} 
they start their international academic career early by pursuing a degree outside of India, which places them on the 'right path' for working abroad as an academic. Up to $\mathrm{PhD}$ level, having a privileged social background may offer a small extra assistance in catching up with the early movers.

\section{Conclusion}

Most of the literature so far has examined international student mobility and the migration of researchers or academics separately. This paper illustrates the importance of studying student and (professional) academic mobility at the same time: working as an academic in another country is to a very large extent explained by the fact of having studied abroad, most often in the same country as the one in which an academic now works. Student and professional mobility among researchers and academics are thus inextricably linked as academic careers are highly path-dependent in geographical terms.

This study finds the following patterns: international academic careers start early and usually follow a certain geographical trajectory for multiple careers steps (including degrees). This usually implies that early study decisions drive the later academic career trajectory. North American or British universities are highly selective in admitting students, which is also reflected in our survey in which academics with the best high school grades chose and had the opportunity to study in these countries. While only very few academics who were able to enter the North American academic market moved to other destinations or even returned after their $\mathrm{PhD}$ or first job experience, British universities are more of an 'academic stepping stone' from where graduates or post-docs continue their career either in North America or move to other destinations in Europe or top institutions in Asia such as Singapore, Japan, Hong Kong, or some newly established institutions in the Gulf. Return to India seems more likely if graduates or academics moved to other destinations outside these Anglo-Saxon academic core countries as those 'second tier' destinations often offer less opportunities for high-quality research and academic work and may have larger cultural or linguistic barriers for Indian-born academics compared to the English-speaking countries.

The concept of path-dependency seems appropriate for describing academic career trajectories. Our analysis shows that international academic mobility becomes increasingly unlikely if (Indian) academics have missed the chance to gain some early study experience abroad. However, under certain circumstances, academics are able to break this pathdependency. Individual ability, which we attempted to measure through the scores obtained at the end of high school national examination, is one such factor moderating the weight of prior mobility choices. Excellent scores compensate, to some extent, for the huge disadvantage represented by the lack of a foreign MA degree in the likelihood of doing one's $\mathrm{PhD}$ abroad; similar results were found for later transitions. In contrast, having highly-educated parents only very slightly helps students with an Indian degree to get a $\mathrm{PhD}$ abroad, thus slightly reducing the gap with those who hold an MA from outside India. The benefit of coming from a privileged background lies rather in the opportunity to have a head start on the international academic path, as parents' education has a significant impact on the likelihood of moving 
abroad at the early stages of the trajectory - for a bachelor's or a master's degree - but not for later career stages.

Furthermore, we found that geographic path-dependency is highly contextual. First, changes in the Indian higher education system are probably responsible for shifts in international mobility patterns between generations. In particular, the younger and middle generations have a less deterministic type of trajectory in terms of geographical locations. Among older cohorts, few moved abroad for the first time for work reasons. In contrast, a substantial share of those under 50 years old finish their entire education in India and move abroad for the first time to take up a first academic employment mostly at post-doc level, with a sizeable proportion of them subsequently returning to India. This is a more recent pattern of mobility, where geographical path-dependency plays a smaller role. We argue in this paper that more and better opportunities for obtaining a high-quality $\mathrm{PhD}$ in India, coupled with an increasing emphasis on international mobility as a requirement for getting a good academic position in India have shaped new and less path-dependent dynamics of the international mobility of Indian-born academics. We also argue that these dynamics are further shaped by the disciplinary context, with natural scientists and mathematicians being the most likely groups to engage in these new forms of mobility.

\section{References}

Ackers, L. (2001) The Participation of Women Researchers in the TMR Programme of the European Commission: An Evaluation, European Commission (DG Research), Brussels.

Ackers, H.L., and E.A. Oliver (2005) "Fixed term positions in the academic career trajectory", CSLPE Working Paper 2005-3, University of Leeds, Leeds.

Ackers, L. (2005) 'Moving people and knowledge: scientific mobility in the European Union', International Migration, 43 (5), 99-131

Altbach, P. G. (1998) Gigantic peripheries: India and China in the world knowledge system, \|n Altbach P.G. (ed.) Comparative Higher Education: Knowledge, the University and Development, Greenwich, CT: Ablex.

Altbach, P. G. (2011) "The academic profession: The realities of developing countries." In Altbach, P.G. (ed.) Leadership for World-Class Universities, New York.

Baláž V and Williams AM (2004) 'Been there, done that': international student migration and human capital transfers from the UK to Slovakia. Population, Space and Place 10(3): 217237.

Baláz, V. and A. M. Williams. (2007) "Path-dependency and path-creation perspectives on migration trajectories: The economic experiences of Vietnamese migrants in Slovakia." International Migration 45.2 (2007): 37-67.

Balter, M. (1999) 'Europeans who do postdocs abroad face re-entry problems' Science Magazine, 3.9.1999. supra note 32. 
Bauder, H. (2015) 'The International Mobility of Academics: A Labour Market Perspective', International Migration 53(1): 83-96

Bercovitz, Janet EL, John M. de Figueiredo, and David J. Teece. "Firm capabilities and managerial decision making: A theory of innovation biases." In R. Garud, P. Nayyyar and Z. Shapira (Eds), Technological innovation: Oversights and foresights (1997): 233-59.

Bourdieu, P. and J.C. Passeron (1985) Les Héritiers : les étudiants et la culture. Paris: Éditions de Minuit. 1964. 183 p.British Council (2012). 'The shape of things to come: Higher education global trends and emerging opportunities to 2020.' London: British Council.

British Council (2012). 'The shape of things to come: Higher education global trends and emerging opportunities to 2020.' London: British Council.

Brooks, R. and Waters, J. (2010) Social networks and educational mobility: the experiences of UK students. Globalisation, Societies and Education 8(1): 143-157.

Carling, J. (2002) Migration in the age of involuntary immobility: Theoretical reflections and Cape Verdean experiences. Journal of Ethnic and Migration Studies 28(1): 5-42.

Carlson, S. (2013) Becoming a Mobile Student - a Processual Perspective on German Degree Student Mobility. Population, Space and Place 19(2): 168-180.

Cassarino, J-P. (2004) "Theorising return migration: The conceptual approach to return migrants revisited." International Journal on Multicultural Societies 6(2): 253-279.

Chang, W. and L. M. Milan (2012) International Mobility and Employment Characteristics among Recent Recipients of U.S. Doctorates, NSF Info brief 30-300, National Center for Science and Engineering Statistics

Chompalov, I. (2000) "Brain drain from Bulgaria before and after the transition to democracy”, paper presented to the Bulgarian Research Symposium and Network Meeting, Atlanta, Georgia, April.

Cohen, J.H. (2004) The Culture of Migration in Southern Mexico. University of Texas Press. Available from: http://www.jstor.org/stable/10.7560/705708

Czaika, M. (2015) Migration and Economic Prospects, Journal of Ethnic and Migration Studies, 41(1): 58-82

David, P. (1985) "Clio and the Economics of QWERTY.” American Economic Review, 75(2), Papers and Proceedings of the Ninety-Seventh Annual Meeting of the American Economic Association, pp. 332-37.

DFID (2011) Social Science Research in India: A Mapping Report, South Asia Research Hub

De Haas, H. (2010) The Internal Dynamics of Migration Processes: A Theoretical Inquiry. Journal of Ethnic and Migration Studies 36(10): 1587-1617.

Department of Trade and Industry (DTI) (2002) Knowledge Migrants: The Motivations and Experiences of Professionals in the UK on Work Permits, DTI, London.

Duncan, B., and Duncan, O.D. (1968). Minorities and the Process of Stratification. American Sociological Review 33:356-64.Dustmann, Christian. (2003) "Return migration, wage 
differentials, and the optimal migration duration." European Economic Review 47(2): 353 369.

Dustmann, C., (2003) "Return migration, wage differentials, and the optimal migration duration." European Economic Review 47(2): 353-369.

Faggian, A., McCann, P. and Sheppard, S. (2006) An analysis of ethnic differences in UK graduate migration behaviour. The Annals of Regional Science 40(2): 461-471.

Federation of Indian Chambers of Commerce and Industry FICCI, (2014) "Higher education in India: moving towards global relevance and competitiveness" Report. New Delhi: India.

Findlay, A.M/ (2011) An Assessment of Supply and Demand-side Theorizations of International Student Mobility. International Migration 49(2): 162-190.

Findlay, A.M., King, R., Smith, F.M., et al. (2012) World class? An investigation of globalisation, difference and international student mobility. Transactions of the Institute of British Geographers 37(1): 118-131.

Franzoni, C., Scellato, G., and Stephan, P. 2014. “The Mover's Advantage: The Superior Performance of Migrant Scientists", Economics Letters 122:89-93

Friedman, T.L. (2006) The World is Flat: The Globalised World in the Twenty-First Century. London: Penguin Books.

Hansen, W. (2003), A Web-based E-Survey on the International Mobility of Scientists and Engineers, Final Report for Brain Drain Project, Brussels, European Commission

Institute of International Education (2010) Open Doors 2009: International Scholars Leading Places of Origin. Available at: http://opendoors.iienetwork.org/?p=150844

Jayaram, N. (2003) "The fall of the Guru: the decline of the academic profession in India." In Altbach, P. G. (ed.) The decline of the Guru: the Academic Profession in Developing and middle income countries. Palgrave Macmillan.

Jayaram, N. (2011) "Toward world-class status? The IIT system and IIT Bombay." In Altbach, P. G., and J. Salmi (eds.) The road to academic excellence: The making of worldclass research universities, Washington DC: World bank Publications

Kapur, D., and McHale, J. 2005. Give Us Your Best and Brightest: The Global Hunt for Talent and Its Impact on the Developing World. Washington: Center for Global Development.

King, R. (2002) “Towards a new map of European migration”, International Journal of Population Geography 8(2): 89-106.

King, R., and E. Ruiz-Gelices (2003) "International student migration and the European 'year abroad': effects on European identity and subsequent migration behaviour", International Journal of Population Geography 9(3): 229-252.

Korys, I. (2003) "Migration trends in selected EU applicant countries: Poland", CEFMR Working Paper 5/2003, CEFMR, Warsaw. 
Kõu, A. and Bailey, A. (2014) 'Movement is a constant feature in my life': Contextualising migration processes of highly skilled Indians. Geoforum 52: 113-122.

Krishna, V.V. (2016). "Science, Technology and Innovation policy in India". Policy brief, Centre for Social Innovation (ZSI), Vienna, Austria. Accessed at:

https://indigoprojects.eu/object/news/183/attach/INDIGO_Policy_Brochure_STI_policy_Vie w.pdf

Millard, D. (2005) The impact of clustering on scientific mobility. A case study of the UK. Innovation. The European Journal of Social Science Research 18(3): 343-359

Mishra, Alya (2013) Brain gain counters brain drain in attracting PhDs, University World News, 18 May 2013, http://www.universityworldnews.com/, accessed 1 October 2014

Musselin, Christine (2004) "Towards a European academic labour market? Some lessons drawn from empirical studies on academic mobility." Higher Education 48(1): 55-78.

Orr D, Schnitzer K, Frackmann E. (2008). Eurostudent III Final Report. Social and Economic Conditions of Student Life in Europe, 2005-2008. W. Bertelsmann Verlag GmbH \& Co. KG: Bielefeld.

Orr D, Gwosć C, Netz N. (2011). Social and Economic Conditions of Student Life in Europe. Synopsis of indicators. Final report. Eurostudent IV 2008-2011. W. Bertelsmann Verlag: Bielefeld.

Page, Scott E. (2006) "Path dependence." Quarterly Journal of Political Science 1(1): 87115.

Pierson, P. (2000) "Path Dependence, Increasing Returns, and the Study of Politics," American Political Science Review 94(2): 251-67.

Rosenmund M., Geiderer D. and S. Kickingereder (2012). Eine Studie zu Berichten österreichischer Erasmus-Studierender. In: Mit Erasmus durch Europa. Österreichische Studierende berichten über ihren Auslandsaufenthalt. Eine Studie, Gesslbauer E, Volz G, Burtscher M (eds). StudienVerlag: Innsbruck, Wien \& Bozen; 25-115.

Sabharwal, M., and R. Varma (2016) "Return Migration to India: Decision-Making among Academic Engineers and Scientists." International Migration 54(4): 177-190.

Sage, J., Evandrou, M., and Falkingham, J. (2013) Onwards or Homewards? Complex Graduate Migration Pathways, Well-being, and the 'Parental Safety Net'. Population, Space and Place 19(6): 738-755.

Samuelson, W., and R. Zeckhauser (1988) Status Quo Bias in Decision Making, Journal of Risk and Uncertainty, 1(1): 7-59.

Saxenian, A. (2007). The new argonauts: Regional advantage in a global economy. Harvard University Press.

Schnitzer, K. and Zempel-Gino, M. (2002) Euro Student:Social and Economic Conditions of Student Life in Europe 2000, Hannover: Hochschul-Informations-System 
Shils, E. (1972) Metropolis and province in the intellectual community, in Shils, E. (ed.) The Intellectuals and the Powers and Other Essays, Chicago: University of Chicago Press.

Thaler, R. (1980) Toward a Positive Theory of Consumer Choice. Journal of Economic Behavior \& Organization, 1(1): 39-60.

Toma, S., and M. Villares-Varela (2015) The Role of Migration and Higher Education Policies in International Academic Mobility: the Case of Indian Researchers, IMI working paper No 123, Oxford: International Migration Institute

Toma, S., M. Villares-Varela, and M. Czaika (2015) Internationalisation and diversification of Indian academic careers, IMI working paper No 121, Oxford: International Migration Institute

UNESCO/UIS (2015) Global Flow of Tertiary-Level Students, www.uis.unesco.org/, accessed 28 June 2016

Unni, J. (2016) "Skill gaps and employability: Higher education in India." Journal of Development Policy and Practice 1(1): 18-34.

Van de Sande, D., Ackers, H.L. and B. Gill (2005). Impact assessment of the Marie Curie fellowships under the 4th and 5th framework programmes of research and technological development of the EU (1994-2002), Brussels, European Commission.

Van Mol, C., and Timmerman, C., (2014) Should I Stay or Should I Go? An Analysis of the Determinants of Intra-European Student Mobility. Population, Space and Place 20(5): 465479.

Waters, J., and Brooks, R., (2011) 'Vive la différence?': The 'international' experiences of UK students overseas. Population, Space and Place 17(5): 567-578.

Williams, A.M., Baláž, V., and Wallace, C., (2004) International Labour Mobility and Uneven Regional Development in Europe Human Capital, Knowledge and Entrepreneurship. European Urban and Regional Studies 11(1): 27-46. 


\section{APPENDIX}

****Table A1 here*** 